\section{(6) OPEN ACCESS}

\title{
Deficiency of the myogenic factor MyoD causes a perinatally lethal fetal akinesia
}

\author{
Christopher M Watson, ${ }^{1,2}$ Laura A Crinnion, ${ }^{1,2}$ Helen Murphy, ${ }^{3}$ Melanie Newbould, ${ }^{4}$ \\ Sally M Harrison, ${ }^{2}$ Carolina Lascelles, ${ }^{2}$ Agne Antanaviciute, ${ }^{2}$ Ian M Carr, ${ }^{2}$ \\ Eamonn Sheridan, ${ }^{1,2}$ David T Bonthron, ${ }^{1,2}$ Audrey Smith ${ }^{1}$
}

\begin{abstract}
- Additional material is published online only. To view please visit the journal online (http://dx.doi.org/10.1136/ jmedgenet-2015-103620).

For numbered affiliations see end of article.
\end{abstract}

\section{Correspondence to} Dr Christopher M Watson, Yorkshire Regional Genetics Service, St James's University Hospital, 6.2 Clinical Sciences Building, Leeds LS9 7TF, UK; c.m.watson@leeds.ac.uk

Received 4 November 2015 Revised 25 November 2015 Accepted 1 December 2015 Published Online First 5 January 2016
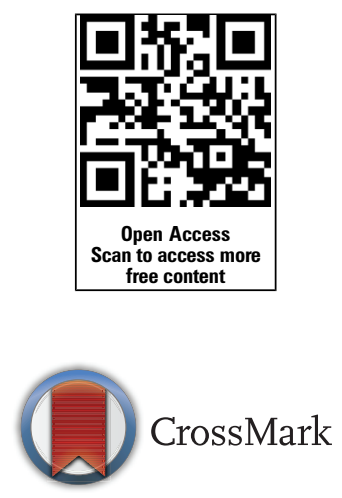

To cite: Watson $\mathrm{CM}$ Crinnion LA, Murphy $\mathrm{H}$, et al. J Med Genet 2016:53:264-269.

\section{ABSTRACT}

Background Lethal fetal akinesia deformation sequence (FADS) describes a clinically and genetically heterogeneous phenotype that includes fetal akinesia, intrauterine growth retardation, arthrogryposis and developmental anomalies. Affected babies die as a result of pulmonary hypoplasia. We aimed to identify the underlying genetic cause of this disorder in a family in which there were three affected individuals from two sibships.

Methods Autosomal-recessive inheritance was suggested by a family history of consanguinity and by recurrence of the phenotype between the two sibships. We performed exome sequencing of the affected individuals and their unaffected mother, followed by autozygosity mapping and variant filtering to identify the causative gene.

Results Five autozygous regions were identified, spanning $31.7 \mathrm{Mb}$ of genomic sequence and including 211 genes. Using standard variant filtering criteria, we excluded all variants as being the likely pathogenic cause, apart from a single novel nonsense mutation, c. 188C >A p.(Ser63*) (NM_002478.4), in MYOD1. This gene encodes an extensively studied transcription factor involved in muscle development, which has nonetheless not hitherto been associated with a hereditary human disease phenotype.

Conclusions We provide the first description of a human phenotype that appears to result from MYOD1 mutation. The presentation with FADS is consistent with a large body of data demonstrating that in the mouse, MyoD is a major controller of precursor cell commitment to the myogenic differentiation programme.

\section{INTRODUCTION}

Lethal fetal akinesia deformation sequence (FADS; OMIM 208150) comprises a spectrum of clinically and genetically heterogeneous disorders that is most commonly detected prenatally, through the routine application of middle-trimester ultrasound scanning. Its clinical features, which are secondary to the lack of fetal movement, include intrauterine growth retardation, arthrogryposis and developmental anomalies such as lung hypoplasia, characteristic facies, cleft palate and cryptorchidism. ${ }^{1}$ Affected babies either die in utero or shortly after birth. The akinesia phenotype can be due to a genetic defect intrinsic to the fetus, but also to nongenetic causes such as maternal myasthenia gravis.
To date, $>20$ genes have been associated with fetal akinesia, representing all modes of inheritance. Many of these genes encode components of neuromuscular pathways, as described in the comprehensive review by Ravenscroft $\mathrm{et} \mathrm{al} .^{2}$

The prenatal presentation of FADS complicates diagnosis. Although anatomical examination, especially using advanced ultrasonographic techniques, ${ }^{3} 4$ can provide important diagnostic information regarding associated malformations such as facial clefting, prognosis cannot necessarily be inferred with certainty. Postmortem examination may result in a more precise pathological classification, but given the aetiological heterogeneity of FADS, a genetic diagnosis (preferably prenatally) remains highly desirable.

High-throughput DNA sequencing has broadened the scope of traditional hypothesis-free genetic investigations from the detection of structural variants using arrayCGH (or low-coverage whole-genome sequencing, 'CNV-seq') to encompass point mutation and small insertion/deletion variant detection using exome sequencing. The methods employed in large multicentre studies of human paediatric phenotypes (such as 'Deciphering Developmental Disorders'5) are now also being applied to large-scale prenatal studies such as the Prenatal Assessment of Genomes and Exomes project. ${ }^{6}$ To perform new gene discovery, these projects rely on ascertaining a large number of trio samples (typically singleton affected cases and their parents) with similar phenotypes. The expectation is that more than one family within the cohort will have a disease-causing mutation in the same gene, allowing a novel gene function to be attributed. Despite the large size of these data sets, it is frequently the case that similarly affected patients can only be identified outside of the study cohort.

The integration of more 'traditional' types of genetic mapping data into the interpretation of genome-wide sequencing data sets permits an alternative approach, in which candidate genes can be filtered using information from a single family. This permits small-scale gene discovery programmes, which may arise directly from data sets accrued in diagnostic laboratories, without the need for large and expensive recruitment programmes. ${ }^{7}$ Filtering on the basis of identity by descent, either explicit from family history, or implicit based on the rarity of a disease or isolation of an ethnic group, is one very powerful genetic approach. 
Here, we report a consanguineous Caucasian family in whom three affected individuals, from two sibships that share the same mother, presented with features consistent with FADS. Exome analysis with homozygosity-based filtering resulted in the identification of MYOD1 as a new gene underlying FADS.

\section{METHODS}

Consultant clinical geneticists clinically examined and reviewed postmortem examination reports that had been undertaken on the deceased babies. DNA was isolated using phenol/chloroform extraction or standard salting out (for blood) protocols, following written informed consent.

Illumina-compatible exome sequencing libraries were generated for samples II:2, III:1 and III:4 using SureSelect v.5 reagents, following manufacturer's protocols throughout (Agilent Technologies, Wokingham, UK). A low DNA input protocol was followed to create the sequencing library for individual III:2 using alternative library preparation reagents (New England Biolabs, Ipswich, UK). The four exome-enriched libraries were pooled in equimolar concentration with either 3 (III:2) or 4 (II:2, III:1 and III:4) other sequencing libraries prepared as part of the laboratory's standard diagnostic testing workflow. Sequencing of each pool was performed using both lanes of a HiSeq2500 rapid mode flow cell, generating paired-end $100 \mathrm{bp}$ sequence reads (Illumina, San Diego, California, USA).

Despite the poor quality material obtained for DNA extraction from the affected individuals (and low DNA yield for sample III:2), the per-patient sequencing summary metrics were comparable to those obtained from the exome library of the unaffected mother (whose DNA source was peripheral blood lymphocytes, our preferred specimen). Notably a minimal number of reads were adaptor trimmed $(\sim 3.5 \%)$ or identified as duplicate read pairs $(\sim 12.4 \%)$ (see online supplementary table S1).

Data processing was performed using an in-house informatics pipeline. Briefly, raw sequence data were converted from bcl to FASTQ.gz format and demultiplexed using CASAVA V.1.8.2. Adaptor sequences were trimmed from per-patient sequence reads using Cutadapt V.1.7.1 (https://code.google.com/p/ cutadapt $/)^{8}$ before being aligned to the human reference genome (hg19) using bwa V.0.7.12 (http://bio-bwa.sourceforge. net). ${ }^{9}$ Sam to bam conversion, duplicate read removal and read sorting based on mapped read coordinates were performed using Picard V.1.129 (http://picard.sourceforge.net). The Genome Analysis Toolkit (GATK) V.2.3-4Lite was used to perform indel realignment, base quality score recalibration and variant discovery, which resulted in variants being saved in variant call format $(\mathrm{VCF})^{10}$ before being annotated with positional, functional and frequency data using Alamut Batch standalone V.1.4.0 (Interactive Biosoftware, Rouen, France). Programs ancillary to the automated pipeline were used to interrogate these data, namely Agile MultiIdeogram (http://dna.leeds. ac.uk/agile/AgileMultildeogram), which was used to determine regions of autozygosity from the per-patient VCF files, and Agile Exome Filter (http://dna.leeds.ac.uk/agile/ AgileExomeFilter), which was used to filter Alamut Batch annotated variant reports using positional and functional parameters. ${ }^{7}$ Interrogation of the Exome Aggregation Consortium data set was performed using the ExAC Browser (http://exac. broadinstitute.org). Manual inspection of aligned sequence reads was performed using the Integrative Genome Viewer V.2.3.57. ${ }^{11}$ The number of sequence reads mapping to each target base was calculated using the GATK DepthOfCoverage walker.
To confirm and genotype the putative pathogenic MYOD1 variant, a $383 \mathrm{bp}$ amplicon was designed and optimised before being Sanger sequenced using an ABI3730 following manufacturer's protocols (Applied Biosystems, Paisley, UK). Each reaction consisted of $0.5 \mu \mathrm{L}$ of genomic DNA $(\sim 500 \mathrm{ng} / \mu \mathrm{L}), 11 \mu \mathrm{L}$ of Megamix (Microzone, Haywards Heath, UK), $1 \mu \mathrm{L}$ of $10 \mathrm{pmol} / \mu \mathrm{L}$ forward primer (dTGTAAAACGACGGCCAGT ACGACTTCTATGACGACCCG) and $1 \mu \mathrm{L}$ of $10 \mathrm{pmol} / \mu \mathrm{L}$ reverse primer (dCAGGAAACAGCTATGACCCTGGTTTGGA TTGCTCGACG). Both primers contained universal sequencing tags (underlined) to allow Sanger sequencing according to our standard laboratory workflows. Thermocycling conditions consisted of $5 \mathrm{~min}$ at $94^{\circ} \mathrm{C}$, followed by 30 cycles of $94^{\circ} \mathrm{C}$ for $30 \mathrm{~s}$, $55^{\circ} \mathrm{C}$ for $60 \mathrm{~s}$ and $72^{\circ} \mathrm{C}$ for $45 \mathrm{~s}$, before a final extension step at $72^{\circ} \mathrm{C}$ for $5 \mathrm{~min}$. Sequence chromatograms were viewed using Mutation Surveyor V.3.2 (SoftGenetics LLC, State College, USA).

\section{RESULTS}

The pedigree structure of the family is shown in figure 1 . Two affected male babies were born to a first-cousin consanguineous Caucasian couple.

The first child (III:1) was delivered following spontaneous labour at $35^{+5}$ weeks. During the pregnancy, a cystic hygroma had been noted at 12 weeks, which subsequently resolved, and polyhydramnios developed during the third trimester. The baby's birth weight was $1.87 \mathrm{~kg}$ (2nd to 9th centile) and his occipitofrontal circumference (OFC) was $33.0 \mathrm{~cm}$ (50th centile). Apgar scores were 1 at $1 \mathrm{~min}$ and 1 at $5 \mathrm{~min}$. He required extensive resuscitation and was ventilator dependent. He had numerous episodes of oxygen desaturation and on day 2 failed to respond to an acute resuscitation for a further hypoxic episode and died. A postmortem examination noted dysmorphic features that included downslanting palpebral fissures, a small chin and square forehead. The toes and fingers were overlapping and the fists were held in a clenched position. The testes could not be palpated in the scrotum. There was a midline posterior cleft palate and lung hypoplasia. (The right and left lung weights were 15.1 and $11.5 \mathrm{~g}$ compared with a normal combined weight of 34.5 g.) There was a right-sided diaphragmatic eventration, although no hernia was identified. There was a mild degree of bilateral renal pelvis distention, more severe on the left $(1.3 \mathrm{~cm}$ in maximum dimension). Microscopically, the fundamental structure of the lungs was normal, but there was a degree of pulmonary hypoplasia. The costochondral junction appeared irregular, and there was centrilobular congestion of the liver.

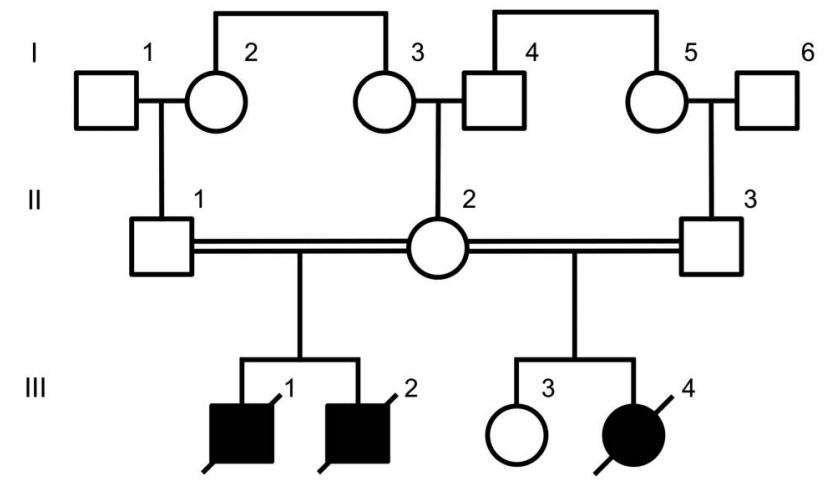

Figure 1 A pedigree showing the relationship between affected (shaded symbols) and unaffected (outlined symbols) individuals. 

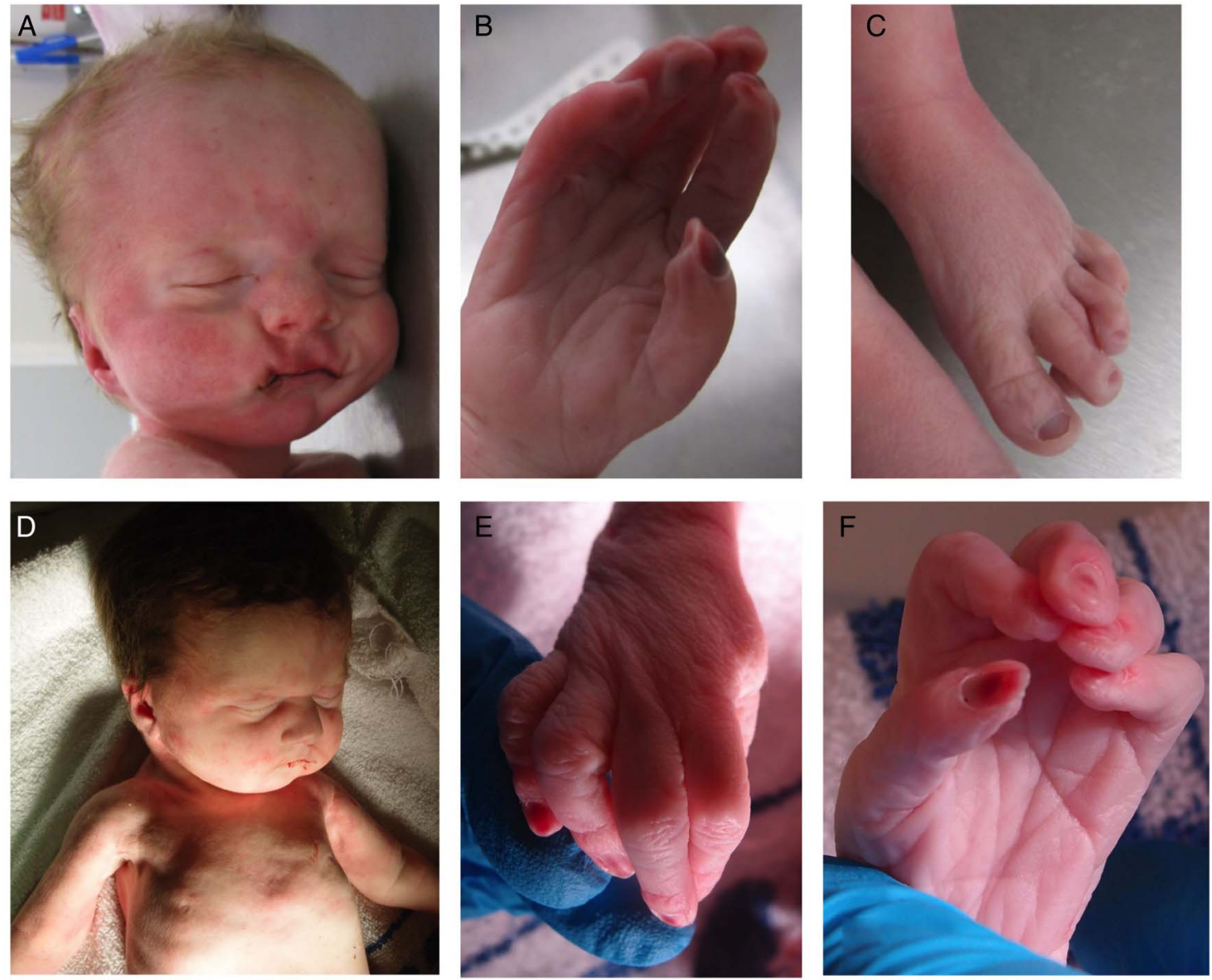

Figure 2 Affected infant III:2 showing (A) facial dysmorphism including a tall forehead with bitemporal narrowing, a long philtrum and a small chin; (B) the right hand showing long tapered fingers with contractures and (C) the left foot with overlapping toes. Affected infant III:4 showing (D) facial dysmorphism including a square forehead and small chin; apparent deficiency of pectoralis and proximal limb musculature (E and F) contractures of the proximal interphalangeal joints in the right and left hand, respectively.

The second child (III:2) was born at $35^{+1}$ weeks following spontaneous labour. During the pregnancy, serial growth scans had detected a right duplex kidney and increased liquor at 28 weeks. A scan at $34^{+2}$ weeks revealed polyhydramnios and gross right-sided hydronephrosis. The baby's birth weight was $1.80 \mathrm{~kg}$ (2nd centile) and his OFC was $33.5 \mathrm{~cm}$ (75th centile). Apgar scores were 1 at $1 \mathrm{~min}$ and 1 at $5 \mathrm{~min}$. The baby died shortly thereafter, following unsuccessful resuscitation attempts. A postmortem examination noted dysmorphic features that included a tall forehead with bitemporal narrowing, a long philtrum and a small chin (figure 2A). He had long tapered fingers with contractures and overlapping toes (figure $2 \mathrm{~B}, \mathrm{C}$ ). A single testis was palpable. There was a midline posterior cleft palate, and the right and left lungs were both extremely small (7 and $5.75 \mathrm{~g}$ ). There was no obvious diaphragmatic hernia, but the domes were very high with extremely small pleural cavities. The right renal pelvis was extremely dilated with an obvious pelviureteric junction obstruction; the left kidney was normal.

The mother next delivered a third baby (III:3) whose father (II:3), a first-cousin relative, was different to that of her previously described affected offspring. The child was healthy.

A further daughter, III:4, was delivered at 37 weeks gestation, following a spontaneous labour. A cystic hygroma had been identified at 12 weeks. Chorionic villus sampling and prenatal arrayCGH analysis revealed no pathogenic CNVs. The baby's birth weight was $1.96 \mathrm{~kg}$ (0.4th to 2nd centile) and her OFC was $32.5 \mathrm{~cm}$ (25th-50th centile). Apgar scores were 1 at $1 \mathrm{~min}$ and 1 at $5 \mathrm{~min}$. Despite intensive resuscitation, the baby died $30 \mathrm{~min}$ after delivery. Postmortem examination revealed a square forehead and small chin (figure 2D). There were contractures of the proximal interphalangeal joints from the 2nd to 5th fingers bilaterally (figure 2E, F). There was also bilateral knee flexion. There was a midline posterior cleft palate and extreme pulmonary hypoplasia. (Right and left lung weights were 8.2 and $6.5 \mathrm{~g}$ ) There was no diaphragmatic hernia, but the domes were extremely high with small pleural cavities. The right and left kidney weights were 3.1 and $8.75 \mathrm{~g}$ (normal combined weight $=17.4 \mathrm{~g}$ ), but no obstruction was identified.

Postnatal arrayCGH analysis of samples III:1, III:2 and III:4 did not reveal any pathogenic variants that could account for the presenting phenotype. The sibling recurrence and reported consanguinity between parents suggested that the disorder was likely to be inherited in an autosomal-recessive manner.

DNA samples from all three affected individuals and their unaffected mother were subjected to exome sequencing.

Having verified the quality control metrics of our data set (see 'Methods'), we undertook autozygosity mapping using exome-wide SNP genotypes. Five genomic regions were identified to be identical by descent, which encompassed $31.7 \mathrm{Mb}$ of genomic DNA sequence and 211 genes (figure 3 and online supplementary table S2). We analysed only homozygous variants located in these autozygous regions, thus reducing the mean 


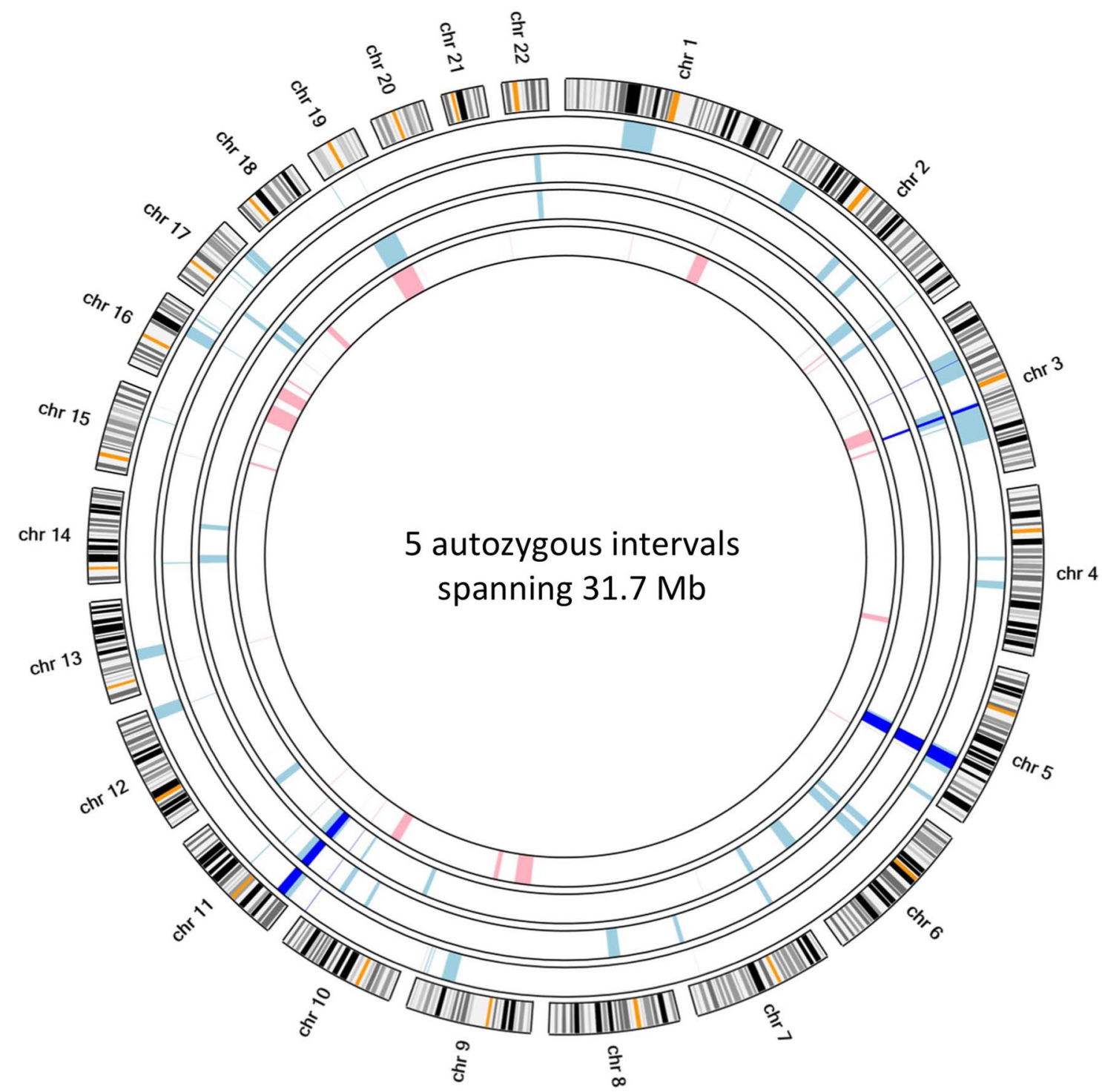

Figure 3 Autozygous intervals shared between all three affected individuals (dark blue) are shown with respect to per-sample autozygous intervals identified in affected individuals (light blue) and the unaffected mother (pink). The concentric circles, beginning from the interior, represent samples II:2, III:2, III:1 and III:4.

total variant count from 35820 to 269 variants per affected individual (table 1). Excluding common variants (those with a minor allele frequency $>1 \%$ in either dbSNP or the ESP5400 data set) further reduced the mean number of variants to 12 . To aid manual interpretation of the remaining variants, we retained only those variants located in coding regions or invariant splice sites. Of these, four variants were identified in a homozygous state in all affected siblings. Two of these were homozygous in the unaffected mother and on this basis were deemed to be nonpathogenic. A further two variants were heterozygous in the mother and warranted further investigation (see online supplementary table S3). The first of these was the missense variant OTOG c.3265A>G p.(Ile1089Val) (NM_001277269.1). Standard in silico tools suggested that this variant was unlikely to be pathogenic. (PolyPhen-2 result: benign; SIFT result: tolerated; AlignGVGD result: class C0.) Furthermore, OTOG has been previously described to cause autosomal-recessive deafness (OMIM: 604487) and did not offer an explanation for the clinical features of our patients. The second variant, MYOD1 c.188C>A p.(Ser63*) (NM_002478.4), was predicted to be pathogenic and would likely lead to nonsense-mediated decay of the mRNA transcript. A thorough search of online databases did not identify this variant in any public databases. Further analysis of 61486 exomes from the ExAC consortium revealed that homozygous loss-of-function (LOF) mutations had not been previously observed in MYOD1. In addition, MYOD1 has not been previously classified as an LOF gene in data sets generated from previous LOF screens. ${ }^{12-14}$

The zygosity status and segregation of the c.188C $>$ A MYOD1 variant was confirmed by Sanger sequencing of six individuals. This included the second father II:3 and his unaffected daughter, III:3, both of whom were heterozygous carriers of the mutation (see online supplementary figure S1).

\section{DISCUSSION}

Here, we define by exome analysis of individuals affected with a perinatally lethal fetal akinesia syndrome, the first human phenotype that appears to be attributable to LOF of the myogenic factor MyoD. MyoD was the earliest described example of a developmental fate-controlling transcription factor ${ }^{15}$ and 
Table 1 Filtering parameters per patient

\begin{tabular}{|c|c|c|c|c|}
\hline Filtering criterion & III:1 & III:2 & III:3 & Mean \\
\hline Total variant count & 36290 & 36304 & 34867 & 35820 \\
\hline $\begin{array}{l}\text { Retain homozygous variants in } \\
\text { autozygous intervals }\end{array}$ & 258 & 269 & 280 & 269 \\
\hline $\begin{array}{l}\text { Retain variants with a dbSNP/ESP5400 } \\
\text { minor allele frequency } \leq 1 \%\end{array}$ & 14 & 13 & 9 & 12 \\
\hline $\begin{array}{l}\text { Retain coding and invariant splice-site } \\
\text { variants }\end{array}$ & 7 & 7 & 5 & 6 \\
\hline
\end{tabular}

has been the subject of intensive study over a period of nearly 30 years. Remarkably though, LOF mutations in human MYOD1 have not previously been identified.

The MyoD family of transcriptional regulators include two primary muscle lineage-determining factors $M y_{o} D$ and $M y f-5$. $M y o D$ expressed from a constitutive promoter is able to convert a variety of different cell types into muscle-lineage cells in vitro. ${ }^{16}$ MyoD is a basic-helix-loop-helix domain-containing protein that functions by binding E-box sequences present in DNA. ${ }^{17}$ Histone acetyltransferases are then recruited to allow chromatin remodelling towards an environment that is conducive to active transcription.

Much work has been undertaken to elucidate the spatial and temporal differences in development between the MyoD/Myf-5 muscle regulatory factors. $M y o D$ mutant mouse embryos show a 2-day delay in the development of hypaxial (limb and abdominal wall) muscle, whereas $M y f-5$ mutants exhibit a similar delay in epaxial (paraspinal and intercostal) muscle development. ${ }^{18}$ However, lineage-tracing experiments combined with selective ablation of MyoD-expressing cells, using diphtheria toxin, indicate that the majority of myogenic progenitors pass through a $\mathrm{MyoD}+$ cell fate and that myogenesis cannot be rescued by embryonic progenitor cells not expressing MyoD. ${ }^{19}$

It is, therefore, somewhat surprising that homozygous $M y o D$ knockout mice are viable and fertile, produce seemingly normal amounts of the downstream myogenin protein and have no histologically detectable muscle abnormalities. ${ }^{20}$ Only when crossed with Myf-5 knockout mice to create homozygous double mutants is a lethal phenotype (with complete absence of skeletal muscle) obtained; this suggests there is an element of functional redundancy between these two muscle regulatory factors. ${ }^{21}$ In contrast to these findings in the mouse, the family we report here suggests that lack of MYOD1 is not compatible with postnatal life in humans.

Why human MYOD1 mutations have not previously been recognised is uncertain, although recessive null alleles, as mentioned above, are clearly very rare. Prenatally and perinatally lethal disorders can be difficult to study because of limited availability and poor quality of DNA from affected individuals. This has led some to focus on analysis of parental samples in order to deduce pathogenic compound heterozygous genotypes in affected fetuses. ${ }^{22} 23$

In the present case, we were able to perform direct analysis of affected individuals' exomes, with interpretation aided by autozygosity mapping, as previously described. ${ }^{24}$ The autozygosity mapping and variant filtering we performed reduced the burden of variant interpretation to just two candidate disease-causing variants. In silico analysis of one of these variants (OTOG c.3265A>G NM_001277269.1) did not suggest a likely pathogenic effect. Furthermore, OTOG had previously been described to cause autosomal-recessive deafness. ${ }^{25}$ The second variant,
MYOD1 c.188C>A (p.Ser63*; NM_002478.4), is predicted to be pathogenic. In addition to introducing a stop codon within the N-terminal basic domain of the predicted protein, the location of this makes it highly likely that the mRNA transcript will be subject to nonsense-mediated decay. No previous homozygous LOF mutations have been identified in MYOD1 in either of two large international projects. As this investigation is based on a single family, additional independent reports are required to confirm the proposed link between MYOD1 mutations and FADS.

Our autozygosity analysis was performed by direct analysis of sequence variants extracted from whole-exome sequence. This is an approach that we have described previously; ${ }^{24}$ although it offers poorer resolution than whole-genome SNP array mapping, it frequently (as here) suffices and can be performed using data sets generated for routine diagnostic purposes. Of relevance to the present case, this method also avoids problems related to poor performance of array-based reagents in the face of DNA samples of poor quality or limited quantity.

\section{Author affiliations}

${ }^{1}$ Yorkshire Regional Genetics Service, St. James's University Hospital, Leeds, UK ${ }^{2}$ School of Medicine, University of Leeds, St. James's University Hospital, Leeds, UK ${ }^{3}$ Genomic Medicine, Manchester Academic Health Science Centre, The University of Manchester, St Mary's Hospital, Manchester, UK

${ }^{4}$ Department of Paediatric Histopathology, Central Manchester University Hospitals NHS Foundation Trust, Manchester, UK

Acknowledgements The authors sincerely thank the family for participating in this study.

Contributors CMW, LAC, HM, MN, SMH, CL, AA, IMC and AS performed experimental and clinical work and data analysis. CMW, ES, DTB and AS designed and directed the project. CMW, DTB and AS wrote the manuscript.

Funding This work was supported by the Medical Research Council grant number MR/M009084/1.

\section{Competing interests None declared.}

Ethics approval The work was carried out in accordance with a study protocol approved by the Leeds East Research Ethics Committee (reference 07/H1306/113).

Provenance and peer review Not commissioned; externally peer reviewed.

Open Access This is an Open Access article distributed in accordance with the terms of the Creative Commons Attribution (CC BY 4.0) license, which permits others to distribute, remix, adapt and build upon this work, for commercial use, provided the original work is properly cited. See: http://creativecommons.org/ licenses/by/4.0/

\section{REFERENCES}

1 Hall JG. Pena-Shokeir phenotype (fetal akinesia deformation sequence) revisited. Birth Defects Res A Clin Mol Teratol 2009;85:677-94.

2 Ravenscroft G, Sollis E, Charles AK, North KN, Baynam G, Laing NG. Fetal akinesia: review of the genetics of the neuromuscular causes. J Med Genet 2011:48:793-801.

3 Macé G, Sonigo P, Cormier-Daire V, Aubry MC, Martinovic J, Elie C, Gonzales M, Carbonne B, Dumez $Y$, Le Merrer M, Brunelle F, Benachi A. Three-dimensional helical computed tomography in prenatal diagnosis of fetal skeletal dysplasia. Ultrasound Obstet Gynecol 2013;42:161-8.

4 Tonni G, Martins WP, Guimarães Filho H, Araujo J. Role of 3-D ultrasound in clinical obstetric practice: evolution over 20 years. Ultrasound Med Biol 2015;41:1180-211.

5 Wright CF, Fitzgerald TW, Jones WD, Clayton S, McRae JF, van Kogelenberg M, King DA, Ambridge K, Barrett DM, Bayzetinova T, Bevan AP, Bragin E, Chatzimichali EA, Gribble S, Jones P, Krishnappa N, Mason LE, Miller R, Morley KI, Parthiban V, Prigmore E, Rajan D, Sifrim A, Swaminathan GJ, Tivey AR, Middleton A, Parker M, Carter NP, Barrett JC, Hurles ME, FitzPatrick DR, Firth HV, DDD Study. Genetic diagnosis of developmental disorders in the DDD study: a scalable analysis of genome-wide research data. Lancet 2015;385:1305-14.

6 Hillman SC, Willams D, Carss KJ, McMullan DJ, Hurles ME, Kilby MD. Prenatal exome sequencing for fetuses with structural abnormalities: the next step. Ultrasound Obstet Gynecol 2015;45:4-9.

7 Watson CM, Crinnion LA, Morgan JE, Harrison SM, Diggle CP, Adlard J, Lindsay HA, Camm N, Charlton R, Sheridan E, Bonthron DT, Taylor GR, Carr IM. Robust 
diagnostic genetic testing using solution capture enrichment and a novel variant-filtering interface. Hum Mutat 2014;35:434-41.

8 Martin M. Cutadapt removes adapter sequences from high-throughput sequencing reads. EMBnet.journal 2011;17:10-2.

9 Li H, Durbin R. Fast and accurate short read alignment with Burrows-Wheeler transform. Bioinformatics 2009;25:1754-60.

10 DePristo MA, Banks E, Poplin R, Garimella KV, Maguire JR, Hartl C, Philippakis AA, del Angel G, Rivas MA, Hanna M, McKenna A, Fennell TJ, Kernytsky AM, Sivachenko AY, Cibulskis K, Gabriel SB, Altshuler D, Daly MJ. A framework for variation discovery and genotyping using next-generation DNA sequencing data. Nat Genet 2011;43:491-8.

11 Thorvaldsdóttir H, Robinson JT, Mesirov JP. Integrative Genomics Viewer (IGV): high-performance genomics data visualization and exploration. Brief Bioinform 2013;14:178-92.

12 MacArthur DG, Balasubramanian S, Frankish A, Huang N, Morris J, Walter K, Jostins L, Habegger L, Pickrell JK, Montgomery SB, Albers CA, Zhang Z, Conrad DF, Lunter G, Zheng H, Ayub Q, DePristo MA, Banks E, Hu M, Handsaker RE, Rosenfeld JA, Fromer $M$, Jin M, Mu X, Khurana E, Ye K, Kay M, Saunders GI, Suner M-M, Hunt T, Barnes IH, Amid C, Carvalho-Silva DR, Bignell AH, Snow C, Yngvadottir B, Bumpstead S, Cooper DN, Xue Y, Romero IG, 1000 Genomes Project Consortium, Wang J, Li Y, Gibbs RA, McCarroll SA, Dermitzakis ET, Pritchard JK, Barrett JC, Harrow J, Hurles ME, Gerstein MB, Tyler-Smith C. A systematic survey of loss-of-function variants in human protein-coding genes. Science 2012;335: 823-8.

13 Sulem $P$, Helgason $H$, Oddson A, Stefansson $H$, Gudjonsson SA, Zink F, Hjartarson E, Sigurdsson GT, Jonasdottir A, Jonasdottir A, Sigurdsson A, Magnusson OT, Kong A, Helgason A, Holm H, Thorsteinsdottir U, Masson G, Gudbjartsson DF, Stefansson K. Identification of a large set of rare complete human knockouts. Nat Genet 2015;47:448-52.

14 Alsalem AB, Halees AS, Anazi S, Alshamekh S, Alkuraya FS. Autozygome sequencing expands the horizon of human knockout research and provides novel insights into human phenotypic variation. PLoS Genet 2013;9:e1004030.

15 Davis RL, Weintraub $H$, Lassar $A B$. Expression of a single transfected CDNA converts fibroblasts to myoblasts. Cell 1987;51:987-1000.
16 Weintraub H, Tapscott SJ, Davis RL, Thayer MJ, Adam MA, Lassar AB, Miller AD. Activation of muscle-specific genes in pigment, nerve, fat, liver, and fibroblast cell lines by forced expression of MyoD. Proc Natl Acad Sci USA 1989:86:5434-8.

17 Berkes CA, Tapscott SJ. MyoD and the transcriptional control of myogenesis. Semin Cell Dev Biol 2005;16:585-95.

18 Kablar B, Krastel K, Ying C, Asakura A, Tapscott SJ, Rudnicki MA. MyoD and Myf-5 differentially regulate the development of limb versus trunk skeletal muscle. Development 1997;124:4729-38.

19 Wood WM, Etemad S, Yamamoto M, Goldhamer DJ. MyoD-expressing progenitors are essential for skeletal myogenesis and satellite cell development. Dev Biol 2013;384:114-27.

20 Rudnicki MA, Braun T, Hinuma S, Jaenisch R. Inactivation of MyoD in mice leads to up-regulation of the myogenic HLH gene Myf-5 and results in apparently normal muscle development. Cell 1992;71:383-90.

21 Rudnicki MA, Schnegelsberg PN, Stead RH, Braun T, Arnold HH, Jaenisch R. MyoD or Myf-5 is required for the formation of skeletal muscle. Cell 1993;75:1351-9.

22 Ellard S, Kivuva E, Turnpenny P, Stals K, Johnson M, Xie W, Caswell R, Lango Allen $\mathrm{H}$. An exome sequencing strategy to diagnose lethal autosomal recessive disorders. Eur J Hum Genet 2015;23:401-4.

23 Shamseldin HE, Tulbah M, Kurdi W, Nemer M, Alsahan N, Al Mardawi E, Khalifa O, Hashem A, Kurdi A, Babay Z, Bubshait DK, Ibrahim N, Abdulwahab F, Rahbeeni Z, Hashem M, Alkuraya FS. Identification of embryonic lethal genes in humans by autozygosity mapping and exome sequencing in consanguineous families. Genome Biol 2015;16:116.

24 Carr IM, Bhaskar S, O'Sullivan J, Aldahmesh MA, Shamseldin HE, Markham AF, Bonthron DT, Black G, Alkuraya FS. Autozygosity mapping with exome sequence data. Hum Mutat 2013;34:50-6.

25 Schraders M, Ruiz-Palmero L, Kalay E, Oostrik J, del Castillo FJ, Sezgin O, Beynon AJ, Strom TM, Pennings RJ, Seco CZ, Oonk AM, Kunst HP, Domínguez-Ruiz M, García-Arumi AM, del Campo M, Villamar M, Hoefsloot LH, Moreno F, Admiraal RJ, del Castillo I, Kremer H. Mutations of the gene encoding otogelin are a cause of autosomal-recessive nonsyndromic moderate hearing impairment. Am J Hum Genet 2012;91:883-9. 